\title{
El Exilio dentro del exilio. Actividad política y cultural de Ricardo Arenales en México (1908-1922)
}

Exile within exile. Political and cultural activity of Ricardo Arenales in Mexico (1908-

\author{
Paola Prieto Mejía \\ Estudiante del doctorado en historia de la UNAM \\ jepprietome@unal.edu.co
}

Resumen: El artículo desarrolla la actividad política y cultural que el escritor y poeta colombiano Ricardo Arenales, más conocido por su último seudónimo como Porfirio Barba Jacob (1883-1942), desarrolló en México, desde su llegada en 1908, hasta su segunda expulsión del país, por razones políticas, en 1922. El texto analiza las condiciones políticas y culturales de Colombia y México, y sobre la base del entrecruzamiento de ambos campos intelectuales, a partir de la migración del poeta, se analizan las condiciones en que se hizo efectiva su vinculación con determinados grupos de intelectuales mexicanos y las razones que llevaron a su expulsión en 1914 y 1922.

Palabras Clave: Intelectuales, Exilio, historia cruzada.
Abstract: The article develops the political and cultural activity that the Colombian writer and poet Ricardo Arenales, better known by his last pseudonym as Porfirio Barba Jacob (1883-1942), developed in Mexico, from his arrival in 1908, until his second expulsion from the country, for political reasons, in 1922. The text analyses the political and cultural conditions of Colombia and Mexico, and on the basis of the interbreeding of the two intellectual fields, from the migration of the poet, the conditions under which its link with certain groups was made effective Mexican intellectuals and the reasons for their expulsion in 1914 and 1922.

Keywords: Intellectuals, Exile, cross history. 


\section{Introducción}

\section{"A mí me destierran de México, pero a México no podrán desterrarlo de mi" Porfirio Barba Jacob.}

El objetivo de este artículo es analizar los vínculos que el escritor y poeta colombiano, Ricardo Arenales, ${ }^{1}$ estableció con el campo político e intelectual mexicano a su llegada al país en 1908, y hasta 1922, año en que se efectuó su segunda expulsión del país, esta vez por orden del presidente Álvaro Obregón.

Seguir los pasos del poeta de un país a otro, y explicar con ello las formas de vinculación política y cultural que estableció con el México revolucionario, me plantea como historiadora el reto de pensar la historia más allá de las fronteras nacionales, pero basándome en el entrecruzamiento de conceptualizaciones y periodizaciones propias de cada una de las historiografías nacionales en juego (ALTAMIRANO, 2005: 9). Es así un ejercicio de historia cruzada en perspectiva transnacional, en el entendido en que analiza los vínculos o puntos de intersección, como los llamarían Werner y Zimmermann, ${ }^{2}$ entre los campos políticos e intelectuales colombiano y mexicano, ${ }^{3}$ y que en este caso están dados por la migración y el exilio de intelectuales y la creación de redes trasnacionales.

Las resistencias, inercias, modificaciones de trayectorias, formas o contenidos, o nuevas combinaciones que pudieron resultar y ser desplegadas en esta intersección son el eje de análisis de este texto. En este sentido se explicará cómo las tomas de posición del poeta, determinadas por su experiencia colombiana, permitieron y/o dificultaron su vinculación con ese nuevo horizonte de expectativas que representaba para él el campo

\footnotetext{
${ }^{1}$ El nombre de pila del poeta fue Miguel Ángel Osorio Benítez. Durante su vida cambió en varias oportunidades de seudónimo. Por ejemplo, a su llegada a México adoptó el de Ricardo Arenales, que cambió años después por el último y más reconocido: Porfirio Barba Jacob. A lo largo de este escrito me referiré al seudónimo que usó en esta primera etapa en México: Ricardo Arenales.

${ }^{2}$ Werner y Zimmermann plantean en los siguientes términos lo que significa intersectar: "This results in a point of intersection where events likely to affect the elements in their presence to various degrees may be produced, according to their resistance, permeability, or malleability relative to their environment. This notion of intersection is thus at the very heart of histoire croisée as we propose to develop it" (WERNER \& ZIMMERMANN, 2003: 16) .

${ }^{3}$ Las categorías de campo intelectual y campo político han sido desarrolladas por Pierre Bourdieu. Con esta se refiere a un sistema predeterminado de posiciones, que exige clases de agentes provistos de cualidades determinadas (socialmente constituidas) (BOURDIEU, 1980, 1995).
} 
político e intelectual mexicano. ${ }^{4}$ Esta particular forma de ser un intelectual fuera de lugar, un conservador colombiano en medio de una Revolución, marcó sus dos expulsiones del país, primero en el gobierno de Venustiano Carranza en 1914, y luego en el de Álvaro Obregón en 1922.

Para tal fin se analizarán, en primer lugar, las condiciones políticas y culturales colombianas que llevaron a Barba Jacob a comenzar su largo viaje en 1908 y dirigir sus pasos a México. Enseguida, se abordará su estadía en Monterrey y su vinculación con el gobernador del estado de Nuevo León, Bernardo Reyes, y su hijo Alfonso, con quienes emprendería sus primeros proyectos editoriales en suelo mexicano. En un tercer momento, se explicarán las condiciones de participación del colombiano en la Revolución mexicana y las razones que lo llevaron a exiliarse en 1914 con la renuncia de Victoriano Huerta y el triunfo de los Constitucionalistas. Para cerrar se abordará su regreso a México en 1918 y los motivos que lo llevaron una vez más al exilio, esta vez por su oposición al gobierno de Álvaro Obregón.

\section{El autoexilio también es exilio, salida de Ricardo Arenales de Colombia}

Miguel Ángel Osorio Benítez nació en 1883 en Santa Rosa de Osos, Antioquia, en el seno de un hogar católico y conservador. El lugar donde nació, un pequeño poblado del nororiente antioqueño; y el ambiente político que marcó su niñez y juventud, la consolidación del régimen católico y conservador de la Regeneración, ${ }^{5}$ definieron su lugar en el espectro político colombiano de principios del siglo XX. Esta situación lo llevó a verse involucrado en la última de las guerras civiles del siglo XIX, la Guerra de los Mil Días (1899 - 1902), del lado conservador, al ser reclutado en 1901 por el gobierno (BARBA JACOB, 1984: 46; CUBEROS DE VALENCIA, 1989: 18).

\footnotetext{
${ }^{4}$ Las categorías campo de experiencia y horizonte de expectativa son tomadas de la apuesta teórica de (KOSELLECK, 1993).

${ }^{5}$ En la historiografía colombiana se conoce como Regeneración al periodo que comprende los gobiernos conservadores de 1886 a 1910, caracterizados por el centralismo a ultranza y la estrecha vinculación con la Iglesia Católica. Según la Constitución de 1886 el partido político que obtuviera el control de la Presidencia podría extender el monopolio absoluto del poder ejecutivo en todos los niveles, como efectivamente venía sucediendo con el control de los conservadores. Esta situación de total exclusión exacerbó el sectarismo político y de manera indirecta aumentó las probabilidades de violencia entre los partidos, lo que llevó finalmente a la Guerra de los Mil Días (BUSHNELL, 2004: 199).
} 
Fui soldado - decía - sin quererlo y sin pensarlo, de una guerra civil; actué en ella como un autómata, porque sí, porque una fuerza superior, el gobierno, después de reclutarme, me obligó a marchar, hoy en un batallón, mañana en otro, en busca de un batallón contrario, de hermanos de la patria, para dispararles al primer encuentro (JARAMILLO MEZA, 1944: 20).

Esta afirmación del poeta pone en evidencia un elemento clave en las formas en que se desarrolló el conflicto colombiano desde el siglo XIX, en donde la pertenencia a uno de los partidos políticos tradicionales no era, en la mayoría de los casos, una elección consciente sino heredada. Si se nacía en el seno de una familia conservadora, de un pueblo conservador, la probabilidad de desarrollar una sensibilidad conservadora era mucho mayor.

Sin embargo, la filiación política del escritor antioqueño no representó para él una convivencia pacífica con las estructuras culturales católicas y conservadoras. Finalizada la guerra, a su regreso a Angostura como maestro de escuela, protagonizó un episodio de ruptura con el alcalde de ese lugar. Sucedió que en 1904 el alcalde Constantito Balvin ordenó decomisar las copias que circularon de su novela "Virginia" por considerar que la historia era un "atentado contra las sanas costumbres" (ÁLVAREZ, 1974: 24; CUBEROS DE VALENCIA, 1989: 21).

Con la Iglesia como principal aliada del régimen conservador colombiano la exclusión de la corriente liberal radical derrotada en la guerra de 1886, podía tornarse en exclusión cultural. ${ }^{6}$ Desde finales del siglo XIX se había emprendido el paulatino reemplazo de la prensa liberal, de los clubes políticos y de las sociedades democráticas radicales por espacios similares ligados a intereses católicos. ${ }^{7}$ De esta manera fueron perseguidas y censuradas las formas divergentes de interpretar, interpelar y plasmar la realidad, sobre la base de un discurso pretendidamente hegemónico que defendía la importancia de la herencia española, el idioma, la religión y la raza, y el papel de la

\footnotetext{
${ }^{6}$ Con el triunfo de los conservadores en 1886 estos se apoyaron en la estructura eclesiástica para llevar a cabo una parte de su proyecto político: el relacionado con la cultura. El objetivo era aislar a la corriente liberal radical derrotada y propiciar la reorganización del campo político sobre la base de su exclusión (LOAIZA CANO, 2011: 400).

${ }^{7}$ El estudio del historiador colombiano (LOAIZA CANO, 2011), afirma en sus conclusiones que las formas de sociabilidad intelectual liberales fueron eliminadas a finales del siglo XIX, y reemplazadas por formas acordes al régimen de la Regeneración.
} 
Iglesia como ente tutelar de la cultura. ${ }^{8}$ Además de esto, la Iglesia fue la encargada de crear y dirigir las instituciones educativas del Estado, controlar los contenidos de la enseñanza, elaborar y censurar los manuales escolares, entre otras funciones que contribuyeron a afianzar su control ideológico sobre la sociedad (URREGO, 2002: 25).

A causa del incidente, Miguel Ángel Osorio abandonó el pueblo y comenzó la travesía que años después lo llevaría a México en 1908. Al respecto dijo:

y un día cualquiera, [...], y creyéndome libre de cualquier atadura, emprendí el viaje como un judío errante, siempre buscando la tierra prometida sin lograr echar raíces en ninguna parte [...] Fue un peregrinaje lleno de episodios inolvidables y que se prolongó en esta primera etapa por veinte años, ya que, a mi patria, de donde me había desterrado por mi propia decisión, únicamente regresaría por corto periodo, entre 1927 y 1930. (CUBEROS DE VALENCIA, 1989: 24)

Destaca de este fragmento la idea de autoexilio, que, aunque no necesariamente puede ser encuadrada en la categoría de exilio político, sí comparten cierto ethos. Al respecto plantea Luis Roniger que el hecho de expatriarse, entendido como una acción voluntaria, a menudo contempla un "fuerte sentido de la coacción" y "proyecta una sensación de alienación hacia un contexto sociopolítico que forzó el alejamiento, que genera la tendencia a usar el término [de exilio] también en forma metafórica" (RONIGER, 2015).

Con este argumento se puede leer la situación de los desterrados, exiliados, expatriados, y por qué no, migrantes colombianos de principios de siglo, más allá de los estrechos márgenes de la imposición que implica la categoría de exilio, y ver en ese amplio abanico de desplazamientos cómo se han colado los motivos políticos. Es posible encontrar puntos de conexión entre quienes sufrieron persecución directa y quienes eligieron el desplazamiento y la expatriación con base en motivaciones políticas y culturales como fue el caso del poeta antioqueño. Al ampliar la mirada se puede tener una perspectiva más compleja de la migración por motivos políticos en la Colombia de principios de siglo, y comprender la estrecha relación que existió entre la migración y el exilio de políticos e intelectuales colombianos, y el triunfo de la

\footnotetext{
${ }^{8}$ Sobre el tema de la censura Shirley Tatiana Pérez presenta un inventario detallado de los periódicos censurados entre 1886 y 1910, y hace un análisis sobre la censura del régimen conservador (2014: 200).
} 
Regeneración y su consolidación, desde finales de la década de 1910, en lo que se conoció como la Hegemonía Conservadora.

\section{¿México, país refugio?}

El inicio del nuevo siglo no había sido fácil para Colombia y contrastaba con la estabilidad política y económica que reflejaba el régimen de Porfirio Díaz, antes de la Revolución de 1910, hacía los países del sur del continente. La derrota del liberalismo colombiano contrastaba con el triunfo del proyecto liberal abanderado por Benito Juárez en México; los desastres que la última de las guerras civiles había dejado en todo el territorio nacional eran el anverso de la Pax porfiriana; y la empobrecida economía colombiana era sobrepasada por mucho por el progreso económico mexicano de esos años. Esta situación sumada al prestigio de la vida cultural mexicana entre los poetas y escritores del contiene hizo que México se configurara como un importante polo de atracción para políticos liberales, pero también para escritores y poetas no necesariamente de filiación liberal.

De esta manera, en el marco de una reducida migración de colombianos a México en los primeros años del siglo XX, ${ }^{9}$ Miguel Ángel Osorio, que para esta época comenzó a usar el seudónimo de Ricardo Arenales, arribó al puerto de Veracruz a mediados de 1908 proveniente de una corta estancia en La Habana. Al parecer su deseo era ir a París, lo que declaró en más de una oportunidad, pero no lo hizo en un principio porque no sabía el idioma. Según él, el escritor hispano-cubano Alfonso Hernández Catá, a quien conoció en su paso por Cuba, le marcó la ruta hacia México (BARBA JACOB, 1984: 58).

El país que encontró el poeta colombiano estaba atravesando por una creciente agitación política que desencadenaría, dos años después, en el movimiento popular más importante de la primera mitad del siglo XX en el continente americano. Las elecciones presidenciales que tendrían lugar en 1910, en las que se verificaría la sexta reelección de Porfirio Díaz, estarían marcadas por una irrefrenable pérdida de legitimidad del régimen, proceso tan fuerte y amplio, según el historiador Alan Knight, como para

\footnotetext{
${ }^{9}$ Cuantitativamente hablando, la migración colombiana a México en la primera mitad del siglo XX resulta insignificante. Según los censos de población para 1900 habitaban en México 73 colombianos; en 1910, 82; en 1920, 182; y en 1930, 273. Datos tomados de: (SALAZAR ANAYA, 1996: 295).
} 
provocar la caída del gobierno y abrir el camino para una revolución genuinamente popular (KNIGHT, 2015: 247). ${ }^{10}$

A este escenario político y cultural en ebullición llegó Ricardo Arenales en 1908. Al poco tiempo de estar en la ciudad de México se dirigió a Monterrey, en donde estableció contacto con el gobernador del estado, Bernardo Reyes. No son muy claras las razones que lo llevaron al norte del país, el caso es que allí se vinculó con la redacción de los periódicos Monterrey News y El Espectador, propiedad del gobernador del estado. ${ }^{11}$ Conoció también por esta época a Alfonso Reyes, ante quien fue presentado, meses después de su llegada a Monterrey, por el director de El Espectador, Ramón Triviño (CAICEDO PALACIOS, 2009: 55). Esta relación marcaría su vinculación con la generación de los jóvenes intelectuales del Ateneo de la Juventud (MONSIVAIS, 1977: 326-331; PÉREZ MONFORT, 2015: 137), aunque desde una posición marginal.

En la primera carta que el colombiano le escribió a Alfonso Reyes le pedía colaborar en su nueva revista, nombrada Contemporánea como homenaje a su homónima colombiana fundada por Baldomero Sanín Cano en 1905 en Bogotá (PINEDA BUITRAGO, 2007: 48). La Contemporánea mexicana fue dirigida por Virgilio Garza y fueron publicados 14 números, de enero a junio de 1909. Durante su publicación tuvo gran apoyo de Alfonso Reyes y Pedro Henríquez Ureña a través de los cuales la revista fue ofrecida a los integrantes del Ateneo para que allí publicaran sus artículos literarios. ${ }^{12}$ Henríquez Ureña afirmaba que si bien la revista estaba mucho mejor de lo que se había imaginado, se veía demasiado extraña para el medio en el que era publicada, por lo que le recomendaba al colombiano trasladarse a la ciudad de México. ${ }^{13}$

\footnotetext{
${ }^{10}$ Para ver un balance completo de las condiciones políticas, económicas y diplomáticas que llevaron a que 1910 fuera un año excepcional en la historia de México ver el análisis que presenta Garciadiego en su ensayo titulado "1910: del viejo al nuevo Estado mexicano" publicado en: (GARCIADIEGO, 2011: 5370).

${ }^{11}$ La correspondencia entre Alfonso Reyes y Pedro Henríquez Ureña deja ver cómo el padre del primero ofrecía empleo a los escritores amigos, como el hermano de Pedro, Max Henríquez Ureña, en dichos periódicos. Alfonso Reyes y José Luis Martínez, "De Alfonso Reyes a Pedro Henríquez Ureña, Monterrey 14 de enero de 1908, Correspondencia. Alfonso Reyes/ Pedro Henríquez Ureña., vol.1 (México : Fondo de Cultura Económica, 1986, 1986), 1:51.

12 "De Pedro Henríquez Ureña a Alfonso Reyes, 22 de enero de 1909, México" (REYES \& MARTÍNEZ, 1986: 128-130).

13 "De Pedro Henríquez Ureña a Alfonso Reyes, 4 de febrero de 1908” (REYES \& MARTíNEZ, 1986: 83).
} 
Pese a la vinculación de Arenales con Reyes a través de la revista Contemporánea, en realidad, el poeta colombiano no fue bien recibido ni por este ni por su compañero Pedro Henríquez Ureña, quienes comenzaron a ver con malos ojos sus excéntricas formas de hacer presencia en el campo cultural mexicano. En una carta del 18 de enero de 1909 Henríquez Ureña le solicitaba a Reyes que le dijera a Arenales que no le escribiera más pidiendo su colaboración, y que de ahora en adelante fuera el intermediario entre los dos. También le decía en esa carta que era una locura la idea que tenía Arenales de regresar a la ciudad de México: "Ya estuvo aquí, y tuvo que irse: ¿a qué vuelve? - le decía - Y eso de la suciedad, que ya sabía, es cosa que le impedirá hacer nada". ${ }^{14}$

Ricardo Arenales no solo no se entendió con Reyes y Henríquez Ureña, sino que los desencuentros con la opinión pública mexicana comenzaron a ser más frecuentes con el paso del tiempo, especialmente después del disfrazado exilio de Bernardo Reyes a finales de 1909, a raíz de lo cual quedó sin su protección y respaldo. Una de las críticas provino del diario mexicano El Debate, en abril de 1910, cuando sus editores reaccionaron a un artículo publicado por el poeta en El Espectador de Monterrey, en donde este supuestamente criticaba a Heriberto Barrón un "excorreligionario" suyo. Al respecto desde El Debate se le dijo: "pero si no está usted contento, si las cosas no marchan al gusto de usted, como en los buenos tiempos de don Bernis, puede irse a Colombia o a Panamá, a donde usted guste. Las puertas de este país abominable están abiertas para todos los hombres que quieran entrar, y no se cierran para los que deseen salir". 15

La situación llegó a tal punto que uno de los artículos que publicó en El Espectador lo llevó a la cárcel el 23 de julio de 1910. Según un testimonio de la época el cierre del diario, la clausura de sus oficinas y el encarcelamiento de su director, se debieron a una orden judicial, ya que al parecer un ciudadano norteamericano se dio por difamado en un artículo publicado por Arenales (GARCÍA AGUILAR, 2010: 8). Otra versión dice que fue confinado porque desde El Espectador dirigió ataques contra el nuevo gobernador del estado de Nuevo León, José María Mier.

La noticia fue seguida con atención por el diario capitalino El Tiempo en donde se comunicó a los lectores que a finales de julio las oficinas de El Espectador habían

\footnotetext{
14 “De Pedro Henríquez Ureña a Alfonso Reyes, México, 18 de enero de 1909” (REYES \& MARTÍNEZ, 1986: 124).

15 “Cabos Sueltos”, El Debate, México, 16 de abril de 1910: 3.
} 
sido cateadas por orden de un juez, y el poeta colombiano, junto con Oswaldo Sánchez, habían sido detenidos y enviados a la cárcel. ${ }^{16}$ Informó también que el lugar donde se imprimía el periódico, la Tipografía Artística, había sido clausurada e inventariados todos los útiles y objetos pertenecientes al periódico. ${ }^{17}$

De la cárcel lo sacó la Revolución el 6 de enero de 1911, tras lo cual se dirigió a la ciudad de México en donde se contactó con los directores de los periódicos El Imparcial y El Independiente.

Estando en la capital, presenció de cerca el complot organizado por los generales Félix Díaz y Bernardo Reyes, cuya experiencia personal terminó plasmando en el libro El Combate de la ciudadela narrado por un extranjero, en la voz de un ciudadano chileno de nombre Emigdio S. Paniagua (PANIAGUA, 1913). Con esto, aprovechó no sólo para criticar, una vez más, al gobierno de Madero, sino para hacer un sentido homenaje al General Reyes a propósito de su muerte, y con ello resaltar la figura del militar que lo acogió en Monterrey bajo su patrocinio.

Así concluyó sus días aquel grande hombre. La posteridad le hará justicia a su patriotismo sin mancha, a su valor, a su pericia como militar...Ella revaluará la obra que él llevo a cabo en el Estado de Nuevo León; ella dirá que, si tuvo errores como político, no los tuvo como mexicano amante de la grandeza de su País. Y ella dirá, por último, que aquel hombre que fracasó en una revolución en que no tenía soldados, halló más tarde la justificación de su conducta al ver que la misma revolución se levantaba por todas partes; y que el que no alcanzó a ocupar la silla Presidencial que honraron el gran Juárez y el insigne Porfirio Díaz, hubiera llevado a ella, cuando menos, su patriotismo, su honradez administrativa, su experiencia de muchos años y su firme voluntad de hacer obra duradera y gloriosa (PANIAGUA, 1913: 2425).

Los argumentos esgrimidos en este relato son compartidos, en términos generales, por aquellos publicados en la prensa por el poeta colombiano. Es de resaltar el esfuerzo que éste hacía por demostrar que el inconformismo contra Madero no venía únicamente de los sectores políticos vinculados con el porfirismo: las élites económicas, políticas y militares desplazadas por la Revolución, sino que existía una oposición desde

\footnotetext{
16 “Las oficinas de El Espectador fueron cateadas", El Tiempo, México, 1 de agosto de 1910: 7.

17 "Pequeñas noticias de los estados”, El Tiempo, México, 4 de agosto de 1910: 4.
} 
los sectores populares, sobre todo urbanos, que se quejaban de la desbandada zapatista, considerada por el poeta una de las principales consecuencias, y la más negativa, de la Revolución.

De la misma manera que apoyó a Reyes también lo hizo con Porfirio Díaz, aspecto común en sus escritos posteriores. Para Arenales, Díaz había sido el gobernador que había encadenado

la anarquía tradicional por espacio de treinta años, y a cuyo amparo restañó México sus heridas, vio florecer sus industrias, creó sus grandes vías de comunicación, organizó la hacienda, disciplinó las voluntades para el trabajo, cimentó el crédito, y adquirió un puesto de honor al lado de los países más cultos de América. ${ }^{18}$

Esta idea sobre Díaz era común entre sus apologistas, y de alguna manera también lo fue entre la prensa extranjera y la burguesía latinoamericana que habían visto con muchas simpatías los logros de la estabilidad política mexicana. Ahora bien, si el gobierno de Díaz había traído paz y prosperidad a México, lo que vino después de 1910 fue para el poeta no más que pura anarquía. Él creía que aunque el movimiento de Madero había roto "efectivamente, los grilletes de una dictadura gloriosa", no se podía negar que también había desatado "la desorientación de los espíritus directores y la zozobra de la multitud". ${ }^{19}$ Para el poeta, citando a Prevost - Paradol, el arte de hacer libres a los pueblos no encarnaba necesariamente el secreto de hacerlos felices". ${ }^{20}$

Por esto no era de extrañarse que la figura de Zapata le resultara tan odiosa. Las imágenes del levantamiento del Ejército del Sur le inspiraban miedo, como a una gran parte de la sociedad capitalina. Por ello en un artículo de 1913 pedía:

"a voces el exterminio de estas fieras humanas que desquebrajan y achicharran hombres, que violan y asesinan mujeres, que azotan y remuelan cráneos de niños y que dejan en el suelo, para remembranza de la orgía macabra, charcos de púrpura, miembros rotos y negruras y pavesas de incendio". ${ }^{21}$

\footnotetext{
${ }^{18}$ Ricardo Arenales, "El regreso del señor General Díaz", El Independiente, México, 19 de marzo de 1913, en: (GARCÍA AGUILAR, 2010: 36-39).

${ }^{19}$ Ricardo Arenales, "Los ideales de la Revolución y el ideal de la patria", Churubusco, México, 13 de mayo de 1914 (GARCÍA AGUILAR, 2010: 69); Ricardo Arenales, "Los ideales de la Revolución y el ideal de la patria", Churubusco, México, 13 de mayo de 1914 (García Aguilar, 2010: 69).

${ }^{20}$ Arenales, "Los ideales de la Revolución..." en: (GARCÍA AGUILAR, 2010: 69).

${ }^{21}$ Ricardo Arenales, “¡Delenda est Zapata!, El Independiente, México, 6 de mayo de 1913 (GARCÍA AGUILAR, 2010: 47).
} 
De sus críticas no escapó la revolución constitucionalista, de la que afirmaba que no haría al pueblo mexicano libre, sino legalista: "Entre las leyes y las libertades no hay paralelismo absoluto. La peor de las tiranías, dijo una vez el Libertador de Colombia, es la que ejercen los magistrados por ministerio de los códigos."(GARCÍA AGUILAR, 2010: 69). Por ello, aunque siguiendo a Bolívar nuevamente, cuando decía que las revoluciones había que verlas de cerca y juzgarlas de lejos, para poder formarse un juicio digno de la posteridad, no dudaba en señalar los primeros fracasos de la revolución: la desorientación de la multitud ante las grandes promesas consignadas en los ideales y reivindicaciones que los caudillos habían azuzado contra el "régimen de los treinta años”. (GARCÍA AGUILAR, 2010: 69).

Así como acusaba a los revolucionarios por el estado de anarquía imperante en toda la República, los culpaba también por la ocupación del Puerto de Veracruz, ya que según él los rebeldes habían suscitado un orden de cosas que ponían al país "bajo los cañones del enemigo tradicional”. (GARCÍA AGUILAR, 2010: 69). Y en lugar de rendir sus armas en pro de la patria seguían en la defensa de sus intereses egoístas. Por esto no es de extrañarse que desde las páginas Churubusco defendiera al gobierno de Victoriano Huerta y lo comparara con otros regímenes atacados por sus compatriotas, como el de Rosas en Argentina o Núñez en Colombia, pero que le habían heredaron bienestar a sus respectivos pueblos. En defensa de Huerta, afirmaba, que su destino estaba trazado por la inquietud del pueblo, a quien tres años de guerra orientaban hacia rumbos que no eran propiamente los de la democracia deseada en 1910. Huerta debía fundar la dictadura, restablecer la paz nacional, poner orden en la administración y devolver así a la República el bien inestimable del sosiego perdido. ${ }^{22}$

Arenales también aprovechó el espacio que le brindaba la prensa mexicana para referirse a su patria. Sobre todo, lo hizo a raíz de la toma del Puerto de Veracruz, que inmediatamente relacionó con aquello que había sucedido apenas 11 años atrás en Panamá. ${ }^{23}$ Trajo a colación toda la experiencia que como colombiano tenía con respecto al actuar de los Estados Unidos, y en un ejercicio de comparación entre ambas realidades publicó un artículo que tituló "Los que nos creen incapaces de gobernarnos,

${ }^{22}$ Ricardo Arenales, "La enmienda Platt y la enmienda Huerta", Churubusco, México, 16 de mayo de 1914. En: (GARCÍA AGUILAR, 2010: 83-88).

${ }^{23}$ Ricardo Arenales, "Después de la conquista de México se hará la de Colombia", Churubusco, México D.F., 6 de mayo de 1914:.1; Ricardo Arenales, "Historia de un acto de piratería internacional llevado a cabo por el coloso del norte", Churubusco, México D.F., 6 de mayo de 1914: 2,4,5; Ricardo Arenales, "Lo que ha significado la conquista del istmo de Panamá por los mercaderes de EEUU", Churubusco, México D.F., 15 de mayo de 1914. 
ignoran la historia de América". ${ }^{24}$ Allí, con la ayuda del ejemplo colombiano debatió la justificación estadounidense para ocupar el puerto, según la cual se hacía para garantizar la estabilidad de los negocios de sus coterráneos, amenazada por la inestabilidad política mexicana. Arenales afirmaba allí mismo que la paz vivida en Colombia después de la Guerra de los Mil Días y la pérdida de Panamá, era una advertencia clara para quienes creían que los pueblos sometidos a largas revoluciones eran presa fácil de conquista. "No nos vengan a hablar de incapacidades. Del fondo de las charcas de sangre puede venir el impulso que nos lleve al restablecimiento de la paz fundada en la Justicia y en la Ley”. Y seguía con su argumento al decir que, así como lo había logrado Colombia, de esa misma manera México "sean cuales fueren los obstáculos con que tropiece, podrá mañana reparar sus estragos, fundar un gobierno netamente nacional y eminentemente legalista, y volver a conquistar el aprecio y el respeto con que el mundo lo distinguiera durante el régimen del General Díaz". ${ }^{25}$

También aprovechó las páginas de la prensa mexicana para hacer críticas al régimen impuesto por los conservadores colombianos. En "La desastrosa administración de los católicos en Colombia”, artículo que publicó en El Independiente, se vio en la obligación de rectificar otro artículo aparecido en La Nación de la ciudad de México en el que se aplaudía al régimen católico por haber ganado en las elecciones para representantes a la Cámara de 1913. "He sentido dolor al leer las imputaciones que en él se hacen al partido liberal, única y postrera esperanza de un pueblo que no quiere resignarse definitivamente a la expoliación de los conservadores". Curiosos posicionamiento de quien, en la última de las guerras civil, por las razones que haya tenido, participó del lado conservador. Criticaba en este artículo la exclusión de los liberales, tanto en la política como en la cultura nacional, y aseguraba que esta actitud de parte del partido en el poder les había costado a los colombianos tres revoluciones, o lo que es lo mismo "el absoluto desprestigio en el exterior, la ruina en el interior, y el sacrificio de cerca de doscientos mil hombres vigorosos, que hacen falta en los campos y en las fábricas". ${ }^{26}$ Por esto, afirmaba, era injustificado el alborozo de los católicos mexicanos ante el triunfo de los sacerdotes colombianos en las elecciones de ese año.

\footnotetext{
${ }^{24}$ Ricardo Arenales, "Los que nos creen incapaces de gobernarnos, ignoran la historia de América", Churubusco, 22 de mayo de 1914: 1 y 4.

${ }^{25}$ Ricardo Arenales, "Los que nos creen incapaces de gobernarnos, ignoran la historia de América", Churubusco, 22 de mayo de 1914: 1 y 4.

${ }^{26}$ Ricardo Arenales, "La desastrosa administración de los católicos en Colombia", El Independiente, México D.F., 23 de junio de 1913. En: (GARCÍA AGUILAR, 2010: 53).
} 
La ruina del país era evidente y, en tanto la exclusión de los liberales era un hecho cierto, absoluta responsabilidad de ellos mismos.

Con esto queda claro como en los primeros años de la Revolución Arenales se ubicó del lado más conservador de la contienda al defender a Díaz, a Reyes y a Huerta, y al criticar tanto a Madero por su ingenuidad, como a Zapata por la supuesta ferocidad de sus tropas. La defensa de estas posiciones, y su incapacidad de adaptarse a ese cambiante México revolucionario, lo alejó de quienes comenzaron a ostentar el poder, y en su lugar se ganó más enemigos que amigos dentro del nuevo régimen, al menos hasta su regreso al país en 1918.

Su posición política le valió un sinfín de críticas, muchas de las cuales llegaron a la redacción de Churubusco en forma de escritos anónimos y amenazantes. "El lenguaje de tales escritos es violento las más de las veces - explicaba Arenales-. Se nos moteja con las más crudas palabras del idioma y hasta se nos amenaza, ora con la horca, ya con el fusilamiento. Los más misericordiosos nos hablan de cárcel". ${ }^{27}$ Desde la prensa capitalina, opuesta a sus planteamientos, se le acusaba también de dirigir un periódico amarillista, pero además extranjero. Argumento con el cual se pretendía desacreditar sus opiniones. $^{28}$

Desde el consulado colombiano se le advirtió a Arenales que, atendiendo al artículo 19 de la Ley Consular vigente, los cónsules

debían evitar todo género de dificultades o conflictos con las autoridades o con los naturales del país en que residan, y que en caso de guerra civil o internacional, sea o no parte en esta última algún país en el cual están acreditados, observarán la más escrupulosa neutralidad y cuidarán de que sea observada por los ciudadanos colombianos. ${ }^{29}$

En atención a esta normatividad, el cónsul colombiano llamó la atención de Arenales por la falta de observancia, de su parte, de una actitud neutral, "tanto en lo que se refiere a la política interior, como al conflicto internacional existente entre la República mexicana y los Estados Unidos de Norte América”. Se le advertía que si

\footnotetext{
${ }^{27}$ Ricardo Arenales, “Los escritos anónimos y la discusión de los problemas nacionales”, Churubusco, 19 de mayo de 1914: 3.

28 "Fue injusto atacar a los veracruzanos", La Patria, México, 29 de mayo de 1914: 1.

${ }^{29}$ Carta del cónsul general de Colombia en México, Julio Corredor Latorre, a Ricardo Arenales, 6 de mayo de 1914, México D.F., AGN, Colombia, Ministerio de Relaciones Exteriores. Diplomática y consular, Consulado de Colombia en México, c. 645, carp. 106, f. 61.
} 
continuaba con esa actitud, el consulado se vería "en la pena de negarle toda protección, en el remoto caso de que llegare a necesitarla, como ciudadano colombiano." 30

Arenales contestó a la solicitud del cónsul, por intermedio de una comunicación verbal de Leopoldo de la Rosa, que lejos de ceder a las súplicas del funcionario si este continuaba en ellas "diría por la prensa su manera de pensar sobre el asunto, lo que no le permití, -según aclaró el consul - para evitar cualquier escándalo que pudiese perjudicar aparentemente a Colombia, dada la excitación del pueblo mexicano en estos momentos". 31

La situación se tornaba aún más crítica a medida que avanzaba el ejército constitucionalista sobre la ciudad de México, al punto que las circunstancias obligaron a Arenales a declarar que no era cierto que ese fuera un periódico pro-huertista. "Carranza y demás jefes, han llegado a la Capital empujados por los fusiles de Francisco Villa [...] $\mathrm{y}$ ante estos hechos no es posible hacerse ilusiones. Por un mendrugo para el hambre de un día no se atreve ningún escritor a quemar sus naves". ${ }^{32}$ No obstante estas declaraciones, las críticas contra los revolucionarios, pero sobre todo los planteamientos en los cuales justificaba el régimen de Huerta no cesaban.

La presión fue tal que el periódico dejó de publicarse a partir de julio de 1914 y Arenales salió exiliado, como lo hicieron muchos otros huertistas, quienes a raíz de la renuncia de Victoriano Huerta el 15 de julio de ese año y la llegada de Carranza al poder ejecutivo a partir de agosto de 1914, decidieron emprender el camino del exilio (AGUILAR CASAS, 2017; GARCIADIEGO, 2011b).

Desde el exilio, Arenales, en una carta que le escribió a su tía abuela en Colombia le decía:

Durante siete años estuve trabajando en México [...]; pero vino después la guerra y yo, metido en el torbellino de la política, tuve que correr la suerte del país. Al entrar la revolución de Carranza y Villa, y después de año y medio de agitación y de peligro, tuve que salir

\footnotetext{
${ }^{30}$ Carta del cónsul general de Colombia en México, Julio Corredor Latorre, a Ricardo Arenales, 6 de mayo de 1914, México D.F., AGN, Colombia, Ministerio de Relaciones Exteriores. Diplomática y consular, Consulado de Colombia en México, c. 645, carp. 106, f. 61.

${ }^{31}$ Informe del cónsul general de Colombia en México, Julio Corredor Latorre, al Ministro de Relaciones Exteriores, 04 de junio de 1914, México D.F., AGN, Colombia, Ministerio de Relaciones Exteriores. Diplomática y consular, Consulado de Colombia en México, c. 645, carp. 106, f. 62-63.

32 "Nota", Churubusco, México, 14 de mayo de 1914: 1.
} 
huyendo para Guatemala. No necesito decirte que en la fuga perdí todo lo que tenía. ${ }^{33}$

La recomposición del poder en México, con el triunfo del constitucionalismo y la renuncia -y huida del país- de Victoriano Huerta, significó para el poeta colombiano, como puede leerse en su testimonio, la interrupción de cierta normalidad que había alcanzado, desde su llegada a México, con las alianzas políticas que había establecido, primero con el reyismo, y luego con el huertismo. Fue víctima así de lo que Sznajder y Roniger (2013: p. 46) han tenido a bien denominar doble exilio, o exilio en serie, que vino a abonar a su primer autoexilio colombiano.

\section{El exilio dentro del exilio}

Cuatro años duró la travesía que llevó a Ricardo Arenales de La Habana, a Nueva York, Guatemala y El Salvador, y de regreso a México. En una carta que había escrito en 1916 desde La Ceiba - Guatemala a Alfonso Mora Naranjo, amigo suyo de la infancia, le decía:

Allá [en Colombia] tienen muchos detalles de la ruina mía, debida a la revolución de México: perdí todo lo que había hecho en el orden material, y después he sufrido. Fuera de México, todo el mundo es miserable. México era el paraíso, Jaauja. Yo vi correr arroyos de leche y miel; yo vi montones de oro y subí a ellos. ¡Ah, mi México adorable y adorado!. ${ }^{34}$

La nostalgia lo llevó de regresó a México en 1918, esta vez, curiosa y contradictoriamente, al servicio del régimen constitucionalista, que lo había exiliado, como redactor del periódico oficialista El Pueblo. ${ }^{35}$ Este desde su fundación, en 1914, se habían convertido en uno de los bastiones del carrancismo, y junto con todo el aparato propagandístico del Estado, estaba enfocado en mejorar la imagen de la

${ }^{33}$ Carta de Ricardo Arenales a María del Rosario Osorio, Nueva York, 21 de febrero de 1916, en: (BARBA JACOB, 1992: 41).

${ }^{34}$ Carta de Ricardo Arenales a Alfonso Mora Naranjo", La Ceiba, 6 de junio de 1916, en: (BARBA JACOB, 1992: 51).

${ }^{35}$ El Pueblo, periódico carrancista tuvo varios directores desde su fundación en 1914 hasta el cierre definitivo de sus oficinas en 1919. Ambos periódicos, por su duración, se convirtieron en los representantes del carrancismo triunfante (MÉNDEZ LARA, 2016;(FIGUEROA DAZA, 2010). 
Revolución y en propagar sus ideales (MÉNDEZ LARA, 2016;(FIGUEROA DAZA, 2010).

La campaña de propaganda del constitucionalismo había iniciado casi a la par con el levantamiento de Carranza contra el gobierno de Victoriano Huerta. Para su ejecución, tanto al interior de México como en Estados Unidos y Latinoamérica, habían sido llamados no solo los intelectuales mexicanos, sino todos aquellos latinoamericanos que sintieran alguna simpatía por el proceso revolucionario y se comprometieran, a través de sus escritos o giras continentales, a contrarrestar la campaña norteamericana de desprestigio a la Revolución

Este espíritu se vio reflejado en los escritos que a partir de 1918 publicó Ricardo Arenales en la prensa mexicana, marcando una clara diferencia con el polemista que fue en Churubusco. Sus artículos de El Pueblo eran prudentes, reflejaban cierta expectativa frente a los avances de la revolución, y defendía a Carranza, haciendo eco de las exigencias que el gobierno hacía a la prensa subvencionada.

Con el cierre de El Pueblo en 1919, el énfasis de sus escritos no volvió automáticamente a ser la política, como lo había sido antes de su exilio. Por el contrario, dejaban ver su interés por rehuir del tipo de temas que le habían causado la expulsión. En ese sentido, desde las páginas de El Heraldo de México comenzó a publicar una serie de artículos amarillistas que hablaban de brujos y caníbales, de asesinatos y secuestros en la ciudad de México, de las reuniones que sostenía en el Palacio de la Nunciatura, entre otras cuestiones más bien superfluas. También contribuyó con un par de artículos a la campaña antidrogas abanderada por dicho periódico. Escribió en contra de la mariguana, la cocaína y el opio, de los que se sabe era asiduo consumidor. ${ }^{36}$

Arenales también se vio impregnado por los discursos latinoamericanistas del momento. En el prólogo de su libro Rosas Negras, publicado en 1920, defendía la idea, común entre los intelectuales de la época, de que a México le correspondía la dirección del movimiento hispanoamericano.

\footnotetext{
${ }^{36}$ Ricardo Arenales, "La dama de cabellos ardientes se bebe la vida de sus amantes", El Heraldo de México, México D.F., 26 de julio de 1919, en: (GARCÍA AGUILAR, 2010: 236-240); Ricardo Arenales, "En pleno reinado de 'El ídolo blanco"”, El Heraldo de México, México D.F., 1 de agosto de 1919, en: (GARCÍA AGUILAR, 2010: 241-246); Ricardo Arenales, "El opio produce primero sueños bellos y visiones plácidas, después pesadillas, y al final la muerte”, El Heraldo de México, México D.F., 3 de agosto de 1919, en: (GARCÍA AGUILAR, 2010: 247-253).
} 
México está al norte, -decía su escrito-, en los confines del mundo de Bolívar; tiene sus raíces que se prolongan hasta más allá del advenimiento de Colón; posee una fisionomía confusa, pero propia y auténtica; se desborda con el paso huracanado de sus guerrilleros, que no es sino indicio de fuerzas sin cauce; ha sepultado dos imperios; y lo que es más importante, acepta la suprema delegación que le hacen con tácita voz los pueblos fraternos (BARBA JACOB, 1984: 74-75).

Destaca el poeta en este pasaje el papel que México se había arrogado como hermano mayor de los pueblos del sur, debido, principalmente, a la posición geográfica que lo enfrentaba al coloso del norte. Como frontera de los confines del mundo de Bolívar, México abanderaba, según él, la defensa de la soberanía de los pueblos fraternos del sur.

Con el asesinato de Carranza en Tlaxcalantongo, y la llegada a la presidencia del general Álvaro Obregón, el poeta colombiano volvió a hablar de política mexicana. En El Demócrata, ${ }^{37}$ por ejemplo, periódico en el que entró a colaborar en 1921, defendió posiciones totalmente contrarias a aquellas que le habían valido la expulsión en 1914. En esta oportunidad, solo por poner un ejemplo, contrario a las críticas que había levantado en contra del Ejercito Libertador del Sur desde Churubusco en 1914, propagó una imagen positiva, y hasta heroica del general Emiliano Zapata. ${ }^{38}$ Esta posición le sirvió, de paso, para criticar a Venustiano Carranza, ahora con el respaldado que el clima anticarrancista de los primeros años de la década de 1920 les brindaba a los opositores del expresidente asesinado. ${ }^{39}$

También se inscribió, a su manera, en el debate de la época: las disputas por el significado del concepto de revolución. Con el triunfo de la Revolución de Octubre, y el entusiasmo que esta despertó en algunos sectores sociales y, en contraposición, el miedo que provocó en otros, la Revolución mexicana comenzó a ser interpelada por esa otra revolución triunfante. Desde Estados Unidos se impulsó una campaña que pretendía igualar un proceso con el otro, con el objetivo de denunciar las supuestas arbitrariedades

${ }^{37}$ El Demócrata, dirigido por Rafael Martínez, con un marcado carácter propagandístico fue concebido como un periódico itinerante, en tanto se trasladó con el Primer Jefe por toda la República hasta que el gobierno logró asentarse definitivamente en la ciudad de México en 1915. Se publicó hasta abril de 1926, fecha en que se clausuró definitivamente.

${ }^{38}$ Ricardo Arenales, "El sacrificio de Emiliano Zapata no ha sido estéril", El Demócrata, México D.F., 10 de abril de 1921 (GARCÍA AGUILAR, 2010: 120-122).

${ }^{39}$ Ricardo Arenales, "La Silueta de Don Pablo", El Demócrata, México D.F., 19 de abril de 1921 (GARCÍA AGUILAR, 2010: 123-126). 
que los revolucionarios mexicanos estaban cometiendo, según ellos, influenciados por el bolchevismo. Mucha tinta corrió sobre si la opción para las revoluciones latinoamericanas debía ser el nacionalismo, del tipo mexicano, o el internacionalismo proletario; o si las trasformaciones sociales debían hacerse de manera gradual, a través de reformas sociales, o de manera violenta y en busca de cambios radicales.

El caso fue que el poeta colombiano aprovechó la oportunidad que le daba el ambiente antibolchevique para afilar su pluma en contra del presidente de la CROM, Luis N. Morones, al que acusaba de ser el "primer líder del bolchevismo mexicano". 40 La estrategia discursiva que utilizó para desprestigiar a Morones, y con ello a los bolcheviques, fue la de disminuir su presencia e importancia en el medio mexicano. Le acusó de ser un "parlanchín de taberna" "una realidad pequeña, opaca, circunscrita y sin trascendencia posible, en el orden de las ideas". ${ }^{41}$ Estrategia muy común a la hora de criticar las organizaciones obreras inspiradas en la revolución de octubre, aunque esto no significara que Morones comulgara con los bolcheviques. El peligro del discurso de Morones, según Arenales, era que contribuía a mantener "la cuarentena diplomática de los Estados Unidos", y con ello la huida de capitales norteamericanos, situación que hacía "más lenta y difícil la marcha del progreso y el advenimiento de la paz al santuario de las conciencias". 42

En un primer momento la crítica a Morones le permitió al poeta colombiano inscribirse, de una manera u otra, en los esfuerzos de la diplomacia mexicana por obtener el reconocimiento de Estados Unidos.(Palacios \& Covarrubias, 2011, p. 205) Pronto, esta crítica lo llevó a dirigir su pluma contra el Secretario de Gobernación, Plutarco Elías Calles. Desde las páginas del recién fundado periódico capitalino Cronos, propiedad de Ignacio Muñoz, denunció la ambición del general sonorense y sobre todo su responsabilidad en el agitado ambiente social que se vivía en el México de inicios de la década de $1920 .^{43}$

Con el cinismo que lo caracterizaba escribió un artículo criticando a la prensa subvencionada, desde Porfirio Díaz hasta Carranza, haciendo caso omiso, al parecer,

\footnotetext{
${ }^{40}$ Ricardo Arenales, "Ecce Homo", El Demócrata, México D.F., 17 de mayo de 1921, en: (GARCÍA AGUILAR, 2010: 147-149).

${ }^{41}$ Ricardo Arenales, "El Bolcheviquismo y la Revolución Mexicana”, El Demócrata, México D.F., 25 de mayo de 1921, en: (GARCÍA AGUILAR, 2010: 150-152).

${ }^{42}$ Ricardo Arenales, "El Bolcheviquismo y la Revolución Mexicana”, El Demócrata, México D.F., 25 de mayo de 1921, en: (GARCÍA AGUILAR, 2010: 150-152).

${ }^{43}$ Ricardo Arenales, "Una Interrogación Angustiosa”, Cronos, México D.F., 16 de junio de 1922, en: (GARCÍA AGUILAR, 2010: 174-176).
} 
que su participación en El Pueblo en 1918, le había dado la oportunidad, no solo de regresar al país luego de cuatro años de exilio, sino de resolver su vida en términos económicos. En dicho artículo afirmaba que Cronos, "primer diario de la mañana, provisto de elementos modernos para su desarrollo, que se opone al gobierno sin tibiezas ni medias tintas", había surgido como respuesta a ese periodismo que, si bien no tenía que lamentar atropellos, estaba virtualmente amordazado, y aparecía ante la opinión pública como un periodismo corrupto y descompuesto. Afirmaba también que como diario independiente no estaba unido a la Secretaría de Gobernación "por el ombligo de los gastos secretos". ${ }^{44}$ En este sentido Cronos, al defender, según el poeta, un programa radicalmente opuesto al de la Revolución, como diario independiente, se convertiría en la prueba definitiva de que el régimen revolucionario sí garantizaba la libertad de pensamiento, como lo aseguraba con insistencia el Secretario de Gobernación. $^{45}$

Fue de esta manera, como una vez más, como lo hiciera desde Churubusco, convirtió en blanco de sus ataques al régimen de la revolución. Sus más mordaces críticas las dirigió en contra de Calles, a quien acusó de utilizar todo su poder como Secretario de Gobernación para enfilar sus pasos hacía la presidencia de la república. ${ }^{46}$ Aseguraba que el general sonorense suscitaba la agitación de los gremios obreros para su beneficio.

Agitación estéril, que asume formas de violencia y que, haciendo de una clase social el único objeto de la solicitud del gobierno, le inmola como víctimas propiciatorias a las demás clases - que forman la mayoría de los habitantes de la república -, sin que, a la postre, los mismos obreros hayan obtenido la realización de uno solo de sus ideales legítimos. De tal suerte, todo el comunismo de México se trueca en una simple máquina de elecciones al servicio del general Calles. $^{47}$

\footnotetext{
${ }^{44}$ Ricardo Arenales, "Sin Coyunda", Cronos, México D.F., 26 de junio de 1922, en: (GARCÍA AGUILAR, 2010: 183-185).

${ }^{45}$ Ricardo Arenales, “'Sí o no?, Cronos, México D.F., 30 de junio de 1922, en: (GARCÍA AGUILAR, 2010: 188-189).

${ }^{46}$ Ricardo Arenales, "Una Interrogación Angustiosa", Cronos, México D.F., 16 de junio de 1922, en: (GARCÍA AGUILAR, 2010: 174-176).

${ }^{47}$ Ricardo Arenales, "Una Interrogación Angustiosa”, Cronos, México D.F., 16 de junio de 1922, en: (GARCÍA AGUILAR, 2010: 174-176).
} 
Aseguraba que Calles estaba usando a las organizaciones obreras para su beneficio, igual que Carranza había movido a los obreros contra Villa y la Convención, ${ }^{48}$ y así como este, los traicionaría en algún momento. Para Arenales el movimiento obrero mexicano no era más que "una marejada artificial provocada con fines políticos, en provecho de hombres egoístas y ambiciosos". ${ }^{49}$ Lo que en $E l$ Demócrata leía como una válvula de escape, los artículos 23 y 123 de la constitución, ${ }^{50}$ ahora los veía como un exceso contra el capital: "la comedia con que se engaña a los mismos obreros y que no es, en resumidas cuentas, sino la preparación de un futuro despotismo". 51

Como puede verse, lo que comenzó como una crítica a Morones, enmarcada en la campaña gubernamental adelantada para contrarrestar la propaganda norteamericana en contra de la revolución mexicana, presuntamente asociada con la revolución rusa, terminó en una dura crítica a la alianza que el gobierno mexicano había establecido con sectores obreros y agraristas para garantizar su permanencia en el poder. Crítica que volvió a poner al poeta colombiano en la mira de los gobernantes revolucionarios.

A raíz de esto, por orden del presidente de la república, Ricardo Arenales fue detenido y enviado a la frontera con Guatemala: "Estaba en un país para él desconocido, sin un centavo en los bolsillos y con el traje que llevaba puesto como todo equipaje". ${ }^{52}$ Una vez más el colombiano había tomado una posición política que lo ubicaba del lado más conservador de la contienda, y que terminó causándole poderosos enemigos.

El 26 de julio de 1922 el cónsul de Colombia en México, Julio Corredor Latorre, informó al Ministro de Relaciones Exteriores en Bogotá que el gobierno mexicano

\footnotetext{
${ }^{48}$ Ricardo Arenales, "Cronos y los obreros", Cronos, México D.F., 18 de junio de 1922, en: (GARCÍA AGUILAR, 2010: 177-178).

${ }^{49}$ Ricardo Arenales, "Cronos y los obreros", Cronos, México D.F., 18 de junio de 1922, en: (GARCÍA AGUILAR, 2010: 177-178).

${ }^{50}$ Ricardo Arenales, "El bolchevismo y la Revolución Mexicana", El Demócrata, México D.F., 25 de mayo de 1921, en: (GARCÍA AGUILAR, 2010: 150-152).

${ }^{51}$ Ricardo Arenales, "Cronos y los obreros", Cronos, México D.F., 18 de junio de 1922, en: (GARCÍA AGUILAR, 2010: 177-178).

52 Carta de Porfirio Barba Jacob a Enrique González Martínez, 15 de diciembre de 1925, La Habana, (BARBA JACOB, 1992:105)
} 
había aplicado el artículo 33 constitucional a Ricardo Arenales por haberse inmiscuido en los asuntos políticos e internos mexicanos. ${ }^{53}$

El artículo 33 se convirtió en la herramienta más expedita con que contó el Estado mexicano para librarse de aquellos extranjeros que consideraba perniciosos y dañinos. Sin embargo, esto no significó que haya sido usado con asiduidad. La voluntad política de firmar una orden de expulsión requería de una coyuntura específica en la que se contemplara "la naturaleza y conflictividad del delito que se atribuía al extranjero, su nacionalidad, la capacidad del potencial expulsado para movilizar influencias que pudieran frenar o revocar la decisión presidencial y, fundamentalmente, la voluntad de hacer evidente el control, las limitaciones y prohibiciones a las que estaba sometido todo extranjero por parte del poder público". 54

Así que, en el marco de la agitada vida política mexicana de los primeros años de la década de 1920 se dio una de aquellas coyunturas. Desde la Secretaría de Gobernación se había externado el propósito de terminar lo que denominaban una "campaña de injurias y falsedades" de la prensa extranjera. Para los efectos de esa campaña en el extranjero ya se había afilado la batería propagandística del Estado a través de las representaciones diplomáticas mexicanas. Hacía el interior quedaba, no solo la misma propaganda, sino de manera complementaria la expulsión, o amenaza, de aquellos extranjeros inmiscuidos en la tarea de difamar al gobierno, como fue el caso de Arenales.

En el informe del cónsul colombiano relataba que no era la primera vez que esto le sucedía al poeta colombiano, recordando los sucesos de 1914 cuando había sido expulsado por la misma razón. Denunciaba de igual manera el oportunismo con el que Arenales había actuado durante sus años en México, ya que, así como había atacado a la revolución, también se había servido de ella, para luego volverla a atacar. Por estas razones el cónsul justificaba su posición de no interceder por Arenales ante el gobierno mexicano, en tanto obedecía "a la creencia de que no debe protegerse a los colombianos

\footnotetext{
${ }^{53}$ Según el artículo 33 de la Constitución de 1917, a los extranjeros no solo les está prohibido inmiscuirse en la política mexicana, sino que el titular del Ejecutivo está facultado para expulsarlos sin necesidad de juicio previo. Según Pablo Yankelevich (2011: 88) este artículo coloca al extranjero en una situación de manifiesta indefensión, "toda vez que por su aplicación se suspenden garantías individuales que la misma Constitución otorga a quienes residen en el territorio nacional".

${ }^{54}$ El trabajo de Pablo Yankelevich, ¿Deseables o inconvenientes?: las fronteras de la extranjería en el México posrevolucionario (2011), hace un análisis detallado de la política migratoria mexicana y en particular de la aplicación del artículo 33 constitucional en la primera mitad del siglo XX.

55 “serán expulsados los extranjeros perniciosos”, El Maestro, México, 1 de mayo de 1921, n², p. 103.
} 
que se inmiscuyan en política interna del país extranjero en que residen, máxime si han recibido, como el señor Arenales, franca hospitalidad y no pocas prebendas de parte de los mexicanos". 56

Efectivamente Arenales no había dudado a la hora de poner su pluma al servicio del mejor postor. En realidad, el oficio de periodista era secundario para él, lo que realmente le llenaba como escritor era su poesía, lo que no significa que haya transitado libremente por un amplio margen de posiciones políticas. En realidad, siempre se movió en los contornos del conservadurismo, en tanto tuvo como líneas inamovibles de su pensamiento, por una parte, su devoción por Porfirio Díaz, que plasmó en más de una ocasión en sus escritos y que le llevó a defender a Huerta en 1914; y, por otra, su creciente desconfianza por al bolchevismo, que le llevó, como vimos, a transitar de una presencia más o menos neutral y apolítica en los primero años de su regreso a México en 1918, a ocupar una vez más su pluma en la critica a los revolucionarios, esta vez en contra de Plutarco Elías Calles y Luis N. Morones, figuras descollantes y protagonistas del México revolucionario de la década de 1920.

Este último exilio llevó al poeta a "asesinar a Ricardo Arenales", haciendo uso de sus propias palabras, y a darle origen a su último más conocido seudónimo Porfirio Barba Jacob. Existen muchas versiones sobre este cambio de nombre, alimentadas muchas de ellas por la imaginación del poeta, y recogidas en varios lugares por sus coetáneos.

\section{A modo de conclusión}

Para finalizar, quisiera establecer unos elementos que a mi parecer contribuirán al debate sobre el exilio intelectual a principios del siglo XX en América Latina. En primer lugar, al referirme a una figura tan particular como la del poeta Ricardo Arenales me llevó a repensar la categoría de exilio político, en tanto, como se dijo páginas atrás, el hastío y la estrechez cultural fue lo que llevó al poeta a abandonar su país de origen en 1908 y encaminarse a México. No fue esta una experiencia exiliar marcada por la persecución política por parte del gobierno, aunque el poeta, en algunos aspectos, la haya vivido así. Contrario a esto, sus salidas de México en 1914 y 1922 sí respondieron

\footnotetext{
${ }^{56}$ Carta del cónsul encargado de Colombia en México, Julio Corredor Latorre, al Ministro de Relaciones Exteriores, 26 de julio de 1922, México D.F., AGN, Colombia, Ministerio de Relaciones Exteriores. Diplomática y consular, Consulado de Colombia en México, c. 646, carp. 108, f. 104.
} 
a un clima político que se tornó adverso a las posiciones políticas que defendió con ahínco desde los medios en los que publicó, y ahí sí vivió el exilio político como tal.

Si nos permitimos leer la situación de los desterrados, exiliados, expatriados, y por qué no, migrantes, más allá de los estrechos márgenes de la imposición que implica la categoría de exilio, y ver en ese amplio abanico de desplazamientos cómo se han colado los motivos políticos, es posible encontrar puntos de conexión entre quienes sufrieron persecución directa y quienes eligieron el desplazamiento y la expatriación con base en motivaciones políticas. Al ampliar la mirada se puede tener una perspectiva más compleja de la migración por motivos políticos en la Colombia de principios de siglo, y comprender la estrecha relación que existe entre la migración y el exilio de políticos e intelectuales colombianos, y el triunfo de Regeneración y su consolidación, desde finales de la década de 1910, en lo que se conoció como la Hegemonía Conservadora.

Un segundo elemento al que deseo remitirme es al desafío que nos plantea a historiadoras e historiadores la escritura de una historia de los intelectuales desde una perspectiva transnacional. Indudablemente el peso de la categoría de campo intelectual y político, y su anclaje en un marco nacional, nos ha llevado a pensar la historia de los intelectuales desde una perspectiva nacional a la que le corresponden conceptualizaciones y periodizaciones propias de cada una de las historiografías nacionales en juego. El desafío es poner en comunicación estos campos, aprovechar los desarrollos historiográficos existentes y construir narrativas que consideren lo nacional no como un marco de análisis, sino como otro más de los elementos a analizar, junto con identidades culturales, políticas, de clase, de género, entre otras. Como lo planteó Seigel la historia transnacional no es que pierda de vista a las naciones, o denueste de ellas, es que las entiende como frágiles, construidas, imaginadas". (Seigel, 2005: p. 63) Esta forma de entender los estudios transnacionales, me permitió comprender que detrás de las dos expulsiones de México que sufrió el escritor colombiano estaba, sí, su pertenencia a un campo político e intelectual nacional, el colombiano, pero que no se podía explicar solo porque era extranjero y no había podido comprender las dinámicas propias del campo mexicano, sino por su sensibilidad conservadora que le llevó en esas dos ocasiones a inclinarse por posiciones enmarcadas de ese lado del espectro político. Aunque podría decirse que salió de Colombia por cierta incomodidad con respecto al régimen católico y conservador de la Regeneración, el cual criticó desde su estancia en México, el llegar a un espacio mucho más liberal que el colombiano, pero además en 
medio de una revolución, hizo que el colombiano se decantara por posiciones políticas conservadoras en el marco de una revolución triunfante. Su conservadurismo político, más que su proveniencia de otro país y la dificultad que ellos trae en la comprensión del espacio político al que se arriba, fue lo que determinó su dificultad para vincularse de manera efectiva a ese campo político extraño.

\section{Fontes}

\section{Archivos}

Archivo General de la Nación, - Bogotá, Colombia

Ministerio de Relaciones Exteriores

Biblioteca Nacional de Colombia

Hemeroteca Nacional

Biblioteca Luis Ángel Arango - Bogotá, Colombia

Archivo General de la Nación - ciudad de México, México

Secretaría de Gobernación

Archivo de la Secretaría de Relaciones Exteriores de México

Sección de Archivo General

Hemeroteca Nacional de México

Biblioteca Nacional de México

Fondo reservado.

Biblioteca Lerdo de Tejada.

\section{Hemerografía}

El Tiempo (1910)

El Debate (1910)

El Independiente (1913)

Churubusco (1914)

El Pueblo (1918)

El Demócrata (1921-1922)

El Maestro (1921)

Cronos (1922)

\section{Referências bibliográfícas}

AGUILAR CASAS, E. (2017). Pensar en México desde La Habana. Los exiliados huertistas en Cuba. En A. Santana \& L. B. Moreno Rodríguez (Eds.), Exilio Iberoamericano. México D.F.: CIALC - UNAM, pp. 61-68.

ALTAMIRANO, C. (2005). Para un programa de historia intelectual y otros ensayos. Argentina: Siglo XXI Editores.

ÁlVAREZ, A. (1974). Poesía y estilo de Miguel Ángel Osorio (Main Ximenez, Ricardo Arenales, Porfirio Barba Jacob) (A dissertation presented to the graduate council 
or the University of Florida in partial fulfillment of the requirements for the degree of Doctor of Philosophy). University of Florida, Gainesville, Florida.

BARBA JACOB, P. (1984). La Divina tragedia. Prólogo del volumen Rosas Negras, (Guatemala, 1933). En Porfirio Barba Jacob. Joyas de la literatura colombiana. (pp. 45-38). Bogotá: Círculo de Lectores.

BARBA JACOB, P. (1992). Cartas de Barba-Jacob / recopilación y notas Fernando Vallejo. Bogotá: Revista literaria Gradiva.

BOURDIEU, P. (1980). Campo de poder, campo intelectual. Itinerario de un concepto. Buenos Aires: Montressor. Jungla Simbólica.

BOURDIEU, P. (1995). Las reglas del arte. Génesis y estructura del campo literario (T. Kauf, Trad.). Barcelona: Anagrama. Colección Argumentos.

BUSHNELL, D. (2004). Colombia: Una nación a pesar de sí misma. Bogotá: Grupo Planeta.

CAICEDO PALACIOS, A. (Ed.). (2009). Alfonso Reyes y los intelectuales colombianos: Diálogo epistolar (1. ed.). Bogotá D.C., Colombia: Siglo del Hombre Editores : Universidad de Los Andes.

CUBEROS DE VALENCIA, B. (1989). Barba. Poeta errante como el viento. Bogotá: Procultura.

FIGUEROA DAZA, J. E. (2010). La propaganda política constitucionalista durante la Revolución Mexicana (Diciembre de 1914-Julio de 1915). (Tesis de Doctorado). Departamento de periodismo, Universidad de Sevilla, Sevilla, España.

GARCÍA AGUILAR, E. (2010). Escritos mexicanos, la prosa periodística de BarbaJacob. México: Fondo de Cultura Económica.

GARCIADIEGO, J. (2011a). Ensayos de historia sociopolitica de la Revolución mexicana. México, D. F: El Colegio de México.

JARAMILLO MEZA, J. B. (1944). El errante caballero del infortunio. Manizales, Colombia: Biblioteca de Escritores Caldenses.

KNIGHT, A. (2015). La Revolución Mexicana. Ciudad de México: Fondo de Cultura Económica.

KOSELLECK, R. (1993). Futuro Pasado. Para una semántica de los tiempos históricos. España: Ediciones Paidós.

LOAIZA CANO, G. (2011). Sociabilidad, religión y política en la definición de la nación: Colombia, 1820-1886. Bogotá: Universidad Externado de Colombia.

MÉNDEZ LARA, F. I. (2016). Venustiano Carranza y la prensa. Un panorama periodístico, 1913-1919. Caleidoscopio, (35-36), pp. 103-143.

MONSIVAIS, C. (1977). Notas sobre la cultura mexicana en el siglo XX. En Historia General de México (Vol. 4). México, D. F: El Colegio de México.

PALACIOS, G., \& COVARRUBIAS, A. (2011). Historia de las relaciones internacionales de México, 1821-2010. México D.F.: Secretaria de Relaciones Exteriores. Dirección general del acervo histórico diplomático.

PANIAGUA, E. S. (1913). El combate de la ciudadela narrado por un extranjero. México: Tipografía artística. Avenida independencia 29.

PÉREZ MONFORT, R. (2015). La apertura al mundo. Entre modernidades y tradiciones. En R. Pérez Monfort (Ed.), México contemporáneo 1808-2014 (Vol. 4). México: Fondo de Cultura Económica. Fundación Mapfre. El Colegio de México, pp. 113-152.

PÉREZ ROBLES, S. T. (2014). Inmorales, injuriosos y subversivos:las letras durante la Hegemonía Conservadora 1886-1930. Historia y sociedad, O(26), pp. 181-208. https://doi.org/10.15446/hys.n26.44502 
PINEDA BUITRAGO, S. (2007). Colombianos relacionados con Alfonso Reyes. Revista Armas y Letras, (56), pp. 40-45.

REYES, A., \& MARTÍNEZ, J. L. (1986). Correspondencia. Alfonso Reyes/ Pedro Henríquez Ureña. (Vol. 1). México: Fondo de Cultura Económica, 1986. (Biblioteca Central PQ7297.R386 A6 1986).

RONIGER, L. (2015). Destierro y exilio en América Latina: Un campo de estudio transnacional e histórico en expansión Fuente: Pacarina del Sur. Pacarina del sur. Revista de pensamiento crítico latinoamericano [en línea], año 7, n. 25. Recuperado de http://www.pacarinadelsur.com/home/abordajes-y-contiendas/318destierro-y-exilio-en-america-latina-un-campo-de-estudio-transnacional-ehistorico-en-expansion\#_edn1

SALAZAR ANAYA, D. (1996). La población extranjera en México (1895 - 1990): Un recuento con base en los censos generales de población. México, D.F.: Instituto Nacional de Antropología e Historia.

SEIGEL, M. (2005). Beyond compare: Comparative method after the transnational turn. Radical History Review, (91), pp. 62-90.

SZNAJDER, M., \& RONIGER, L. (2013). La política del destierro y el exilio en América Latina (L. Rayas, Trad.). México: Fondo de Cultura Económica.

URREGO, M. Á. (2002). Intelectuales, estado y nación en Colombia: De la Guerra de los Mil Días a la constitución de 1991. Siglo del Hombre Editores.

WERNER, M., \& ZIMMERMANN, B. (2003). Histoire Croisée: Between the Empirical and Reflexivity. Annales. Histoire, Sciences Sociales, 58th Year(1), pp. 7-36.

YANKELEVICH, P. (2011). ¿Deseables o inconvenientes?: Las fronteras de la extranjería en el México posrevolucionario. Bonilla Artigas Editores.

Artigo recebido em 02 de setembro de 2019.

Aprovado em 19 de novembro de 2019.

DOI:10.12957/intellectus.2019.45008 